\title{
SECOND AND FOREIGN LANGUAGE WRITING AND COMPUTER- MEDIATED COMMUNICATION: A QUALITATIVE META-SYNTHESIS OF RECENT RESEARCH
}

\author{
Linda TAY \\ Yin Ling CHEUNG* \\ 1,2 Nanyang Technological University, Singapore \\ ${ }^{1}$ send.to.linda@gmail.com \\ ²yinling.cheung@nie.edu.sg*
}

Manuscript received 6 July 2019

Manuscript accepted 25 Nov 2019

*Corresponding author

10.33736/ils.1477.2019

\begin{abstract}
The use of computer-mediated communication (CMC) in the classroom is common nowadays. The bulk of literature produced so far has done little in informing us the factors that facilitate the role of $\mathrm{CMC}$ in language writing, and the nature of the interaction that takes place via $\mathrm{CMC}$ in a systematic manner. This paper examines what empirical research has found out about the factors that facilitate the use of $\mathrm{CMC}$ in second/ foreign language writing instruction and learning, and the nature of interaction that takes place via CMC in an educational context. 60 peer-reviewed published primary studies from 2007-2017 were reviewed. The key findings are as follows. First, instructor support plays a critical role in ensuring the successful implementation of a CMC tool in the classroom. Second, the affordances of CMC in enhancing the writer's identity and the presence of an audience can increase learners' motivation to write. Third, both asynchronous and synchronous CMC have shown to be beneficial, and the provision of training can further enhance the effectiveness of peer reviews. Last, the participatory patterns of CMC in writing are influenced by factors such as task type, personal goals, native-speaker status, and self-perceived competencies. Pedagogical implications are suggested.
\end{abstract}

Keywords: computer-mediated communication, second and foreign language writing, qualitative, meta-synthesis

Second and Foreign Language Writing and Computer-Mediated Communication: A Qualitative Meta-Synthesis of Recent Research 


\section{Introduction}

Writing with the help of $\mathrm{CMC}$ has increasingly come under the spotlight for its potential in developing second language (L2) written literacy. For one, with CMC, opportunities to learn to write are no longer restricted to the classroom and its time constraints (Chao \& Lo, 2011; Vurdien, 2013). Interaction and peer feedback are also possible (Vurdien, 2013), and Chapelle (2009) notes that in CMC, the written form is often the mode of interaction, and how technology influences the type of linguistic input and how learners access different input forms can impact language acquisition.

A result of $\mathrm{CMC}$ facilitating the writing process is the possibility of collaborative writing, and research on CMC in collaborative learning has highlighted its heightened socio- cultural role mediated by the affordances of technology. Collaborative writing is not limited to student-student partnerships but can also include instructor-student interaction. The increasing level and extent of collaboration inevitably throw up questions of ownership, authorship, and audience (Kessler, Bibowski, \& Boggs, 2012), especially when the role of the learner is greatly expanded from a solitary writer, to one who is both a writer and an active reader (Chao \& Lo, 2011). While Storch (2011) regards joint ownership of the production as "the defining trait of collaborative writing" (p. 275) and excludes aspects such as group-planning and peer-feedback activities from the definition, the existing literature that focus on these very factors show that there is no consensus to the problem. Moreover, with collaborative writing being a social activity, motivational, affective and perception issues are also factors that may influence how technology and $C M C$ impact the second and foreign language writing process. Given the multiple issues surrounding $\mathrm{CMC}$ in writing instruction and learning, and the growing body of literature exploring various aspects of this relationship, this review aims to consolidate and consider the findings of these studies, looking at all aspects of the effect of $\mathrm{CMC}$ on the writing process, from planning to the finished product. It will also examine the socio-cultural aspects of interaction and motivation. Hence, this meta-synthesis of previous research aims to investigate the following research questions:

i. What are the factors that facilitate the role of $\mathrm{CMC}$ in second and foreign language writing?

ii. What is the nature of the interaction that takes place via $\mathrm{CMC}$ in such a context?

iii. How do educators and learners perceive the role of $\mathrm{CMC}$ in the language classroom?

\section{Methodology}

In the search and identification of primary studies to be included in this paper, Lin's (2015) method, which was itself adopted from other meta-synthesis studies (Li, 2010; Sauro, 2011) was used, in line with recommendations on literature search methods for meta-analyses (Oswald \& Plonsky, 2010). Firstly, using keywords such as "computer-mediated communication", "CMC", "second language writing" and "L2

Second and Foreign Language Writing and Computer-Mediated Communication: A Qualitative Meta-Synthesis of Recent Research 
writing" in tandem with Boolean search methods, a search was conducted on electronic databases in the disciplines of linguistics, applied linguistics, social sciences and humanities, language education, and language education using technology. Some of these electronic databases included the Linguistics and Language Behavior Abstracts (LLBA), JSTOR, ERIC, Web of Science, ProQuest, SpringerOpen, and Taylor \& Francis. This step achieved two aims: it enabled the researcher to retrieve the first wave of journal articles and at the same time, it helped to identify key journals in which primary studies and meta-syntheses related to $\mathrm{CMC}$ and second-language writing (SLW) that was not limited to English appeared, and in so doing facilitated the second step of narrowing the searching to individual electronic journals. Some of the journals included in the search were Applied Linguistics, Language Learning \& Technology, System, CALICO Journal, Journal of Second Language Writing, and Computer Assisted Language Learning. Finally, references related to SLW and CMC from the retrieved journal articles were individually identified and retrieved online. By culling the collection to only those from a decade, i.e., 2007 to 2017, a total of $60^{2}$ peer-reviewed published primary studies were obtained.

\section{Findings}

Reflecting Ducate, Anderson, and Moreno's (2011) list of some of the most popular Web 2.0 technologies that include communicative, collaborative, generative, documentative and interactive tools, the studies included in this review looked at the following tools used in second and foreign language writing processes: electronic mail, blogs, collaborative word processors like Google Documents, instant messaging software, social media websites, forums, automated writing evaluation tools, and wikis. We categorised the rising issues and concerns with regard to CMC into five claims.

\section{Claim 1: Carefully Designed and Monitored CMC-Enhanced Tasks with Instructor Support Can Greatly Facilitate the Role of CMC in SLW}

The empirical studies reviewed in this paper found the role of $\mathrm{CMC}$ to be largely facilitative, and one of its affordances is in the allocation of attentional resources to meet the cognitive demands of the writing process. Such cognitive support can come through the broad categories of planning, instructor-given directions and task design. While a number of studies in this review investigated the effects of support of CMC on learners' written production, other studies recommend some form of facilitation in order to maximize computer-mediated learning opportunities and language acquisition.

\footnotetext{
2 Based on published meta-synthesis papers, 60 is the recommended number of articles reviewed by the researchers (Ng \& Cheung, 2017, 2019). Please refer to the methodology section for more information on the selection criteria of the articles.
}

Second and Foreign Language Writing and Computer-Mediated Communication: A Qualitative Meta-Synthesis of Recent Research 


\section{Planning: rehearsal and online.}

A common notion of planning is of one that takes place before the actual speaking or writing task, with this type of pre-task planning involving either a step-by-step rehearsal of the task to be carried out, or one that is more strategic and focuses more on the content (Ellis, 2005; Ortega, 1999). However, planning can also be done online. With $\mathrm{CMC}$, the affordances of online planning are greatly expanded. While the synchronous nature of $\mathrm{CMC}$ bestows upon the writing process in text chat characteristics of speaking such as the possibility for overlapping turns, it is not a simple hybrid of both production modes (Adams, Alwi, \& Newton, 2015). Compared to speaking, CMC allows for a greater amount of lag time between turns, which can be utilized for online planning (Sauro \& Smith, 2010). Coupled with the written form preserved as a visible, enduring trace that is available to the learner for linguistic reflection, this implies that the additional time to process visual input and monitor their output may have a positive impact on language acquisition (Sauro and Smith, 2010).

A small number of studies investigated the effects of planning on the quality and quantity of the text produced. Sauro and Smith's (2010) study leveraged on the screen- capture feature of a software that recorded exactly what appeared on the screen in real time, allowing participants to view deletions, which they investigated for evidence of online planning. What they found were higher levels of linguistic complexity and lexical diversity in the final text production compared to the deleted text, which may suggest that the additional time for online planning was used for the production of more complex language. Going a step further, Hsu (2017) looked into combining online planning with rehearsal, and found that while learner' performances in a new task showed linguistic gains in terms of complexity, the extent of accuracy was also higher than from online planning alone. Since it is hypothesized that in the first performance of a task, the content of the message gets cognitive priority over the linguistic tools needed to convey the message, the value of rehearsing or repetition can be seen in freeing up attentional resources to attend to the linguistic demands of the task after having dealt with the bulk of the content of the message, hence resulting a higher extent of accuracy in the actual task (Amiryousefi, 2016; Bygate, 2001).

\section{Informed classroom management strategies and task design.}

A number of the studies suggest that a limited extent of teacher intervention before, during, and after the task is one of the most critical factors in determining the success of a particular CMC tool in the language classroom. Teachers are able to render better support to learners due to teacher intervention in collaborative tasks, and teacher's awareness of the advantages of CMC-facilitated tasks (Bibowski \& Vithanage, 2016). This teacher-initiated support can come in the forms of informed classroom management strategies and task design.

Firstly, how the task is set up can facilitate learners' ease with the CMC tool in the writing process. Chao and Lo (2011) stress the importance of setting up the learning environment such that learners are well-prepared to work collaboratively

Second and Foreign Language Writing and Computer-Mediated Communication: A Qualitative Meta-Synthesis of Recent Research 
online. To facilitate the use of $\mathrm{CMC}$ tools in the classroom, teachers have to demonstrate that the social skills from collaborative work may go online, and has real-life implications and uses in their professional lives (Elola \& Oskoz, 2010).

While the CMC tool to be used in the task may depend on the objectives of the writing task, the ease of use is important as it impacts time management and preparation efforts (Chao \& Lo, 2011). The choice of CMC tool should also factor in the purpose of incorporating it into the curriculum; having a clearly articulated link between the $\mathrm{CMC}$ tool and what students need to learn could reduce the likelihood of both instructor and learners treating the CMC task as extra work (Cheng, 2010). The next step could involve a deliberate and consistent approach in training learners in pre-task workshops to use a particular CMC tool to encourage maximum engagement in the learning task (Lee et al., 2013; Li, M., 2013), as familiarity with Web 2.0 tools may not translate to ease of use with such tools for pedagogical purposes (Dippold, 2009). For example, Rouhshad, Wigglesworth and Storch (2016) recommend exposure to models showing successful negotiations can increase the frequency of negotiations. Hwang et al. (2014) also found that using contextual situations that were familiar to learners in mobile device usage motivated them to write by reducing their anxieties. In public internet forums, the level of interactivity cannot be controlled and a lack of response may decrease motivation to continue participation (Ritchie \& Black, 2012). Arnold, Ducate, and Kost (2012) also suggest having class discussions on guidelines on peer reviews. One area to consider could be the language used in discussions. The target language would allow learners to develop their communication skills, but it would restrict their language expressions, and this may potentially prevent deeper discussions (Strobl, 2014).

The most ideal conditions would probably be one where learners are given some guidelines on task execution, but a high extent of autonomy to operate within these boundaries. Ducate et al.'s (2011) evaluation of their study led them to recommend having a less structured approach so as to allow students to exercise some control over parts of the assignment. Similarly, Kessler and Bibowski (2010) documented an unexpected use of the wiki project, which showed that students' use of technology may differ from what the instructor expects, and hence some extent of flexibility should be allowed. Flexibility should also be exercised and autonomy given to students to determine the manner of their contributions.

\section{Task support.}

Depending on what the pedagogical focus of the task is, well-considered task designs can help to free up attentional resources for learners to attend to the task at hand. Linguistic support that includes lexical and syntactic items rendered to learners can work in tandem with the affordances of CMC to assist learners in achieving higher levels of accuracy (Ducate et al., 2011; Lee, 2010). Castañeda and Cho (2013) recommend using social software such as videos in pre-task activities to elicit lexical items and grammatical structures needed for the writing task. The teacher's role may even include putting aside assumptions of their students being naturally adept users of digital technologies and guiding them in understanding and using CMC tools in the classroom (Elola \& Oskoz, 2017).

Second and Foreign Language Writing and Computer-Mediated Communication: A Qualitative Meta-Synthesis of Recent Research 
Besides vocabulary, other pre-task support activities that focus on task structure and form were also found to reduce the cognitive burden on the learner, resulting in better performances in specific aspects of writing. Alwi, Adams, and Newton (2012) found that there was more attention to form when task structure support was rendered, thus lowering task complexity and allowing learners to allocate more attentional resources to attention to form. The converse is true as well. Having language-focused pre-task activities also helped learners in their study to focus on form. Similar findings were obtained from Adams et al.'s (2015) study, which investigated the effects of different task implementation conditions on the accuracy and complexity of learners' text chat. Learners were split into four groups with different experimental set-ups, and it was found that a higher level of accuracy was observed in the text chats of those provided with structural support, as well as those with language support. However, the subset of learners who received both structural and language support was able to produce target-like structures more often.

Yilmaz (2011) notes that the much lower focus on form in his study could have been a result of the absence of pre-task mini lessons that could have raised the learners' awareness to the target structure, as well as explicit encouragement to discuss aspects of language. In the same vein, Kessler (2009) suggests that instructors offer a limited amount of support so as to encourage attention to form without interfering with student interaction patterns.

\section{Task design.}

The use of CMC should also be tailored to the student's learning needs (Chen \& Brown, 2012). The aim of Chen and Brown's study (2012) was to obtain findings that could contribute to the design of language lessons with tasks that are beneficial to students. Tasks should probably be challenging yet possible to complete and allows for learner autonomy and is meaningful so that learners are motivated to do it (Chen \& Brown, 2012). Authenticity may play a role. For example, in Dippold's study (2009), the real-world use of a CV task motivated the learners more than the summary task, which was perceived as academic.

Certain task types which demand more negotiation for meaning for task completion seem to be more adept at facilitating collaborative work between learners. Yilmaz (2011) investigated the effects of two different task types on the number and characteristics of language-related episodes (LREs). The tasks, a dictogloss and a jigsaw activity, showed that the dictogloss elicited more LREs than the jigsaw task. Also, the proportion of correctly solved LREs were found to be in the dictogloss than in the jigsaw task, which also had more unresolved LREs. Aydin and Yildiz (2014), working on the premise of the nature and type of task having an influence on the writers' focus on form versus content, and the amount and type of interaction among writers during collaborative writing, examined both form-focused and content-focused task types. They found that tasks that were focused on meaning, cognitively more demanding and open-ended had positive effects on learners' writing. Firstly, meaning-focused task types, such as argumentative,

Second and Foreign Language Writing and Computer-Mediated Communication: A Qualitative Meta-Synthesis of Recent Research 
informative and decision-making writing tasks, resulted in more content-focused changes, though form-focused changes were also present. The results could be attributed to the design of the tasks, which required requesting and supplying of information to achieve a common goal. Secondly, cognitively more demanding tasks, such as argumentative and decision-making activities, resulted in more peer corrections than self-corrections, as learners had to engage in more negotiations in order to solve problems. Lastly, open-ended tasks that allowed opportunities for learners to engage in problem solving increased collaboration through mutually paying attention to each other's contributions (also Li, 2013). Although in Andujar's (2016) study CMC was used as a medium for student interaction during and instead of the actual writing task, he similarly argues that such chat-based interaction gives rise to the opportunity for LREs, which in turn contribute to knowledge construction and language development.

Some studies also recommend designing tasks to facilitate and encourage peer feedback, another crucial aspect of collaborative work. Yeh (2014) suggests having the entire process of collaborative writing in mind when designing tasks. This is likely to get learners to think about the meaning of the text, and motivate them to go beyond focusing on surface features such as errors, which normally happens when co-editing takes place in the last stage. Likewise, Yeh, Lo, and Chu (2014) suggest that it is important to design interactive tasks that would encourage corrective feedback and peer review in writing.

To sum up, the role that the instructor plays can have an impact on the successful implementation of CMC tools in the writing classroom. The instructor should consider the task design, spells out the requirements, scaffolds the task with appropriate support, and allows student autonomy within this set-up.

\section{Claim 2: CMC Increases Motivation by Enhancing and Expanding on The Identity of The Writer, and Opportunities to Engage an Authentic Audience}

The identity of the writer is another aspect which has been found to have an influence on the writing process. When learners were allowed to blog about topics of their choice within the context of their academic writing experiences, they used their blogs to reflect on their identity as $L 2$ writers, focusing on their concerns about writing (Sun \& Chang, 2012). Feelings of solidarity and self-awareness were also greatly bolstered, spurring them to continue blogging in the writing project. When learners felt that their work was central to the completion of the final product, their intrinsic motivation improved (Arnold et al., 2012).

$\mathrm{CMC}$ may also influence the playing out of the writer's identity in the larger social realm, as suggested by Gebhard, Shin, and Seger (2011). Their study, which investigated the influence of blogs as a CMC tool in the development of L2 literary among L1 Spanish Puerto Rican elementary school students, found that blogs were used by students as an extension of their real-life social connections, which entails the power dynamics, status and identities inherently embedded and expressed in these networks. Because of $\mathrm{CMC}$, the playing out of these identities and roles were not limited to physical space and time. The focus student gained confidence from her adept ability to use technology, and this acted as a motivator in her writing

Second and Foreign Language Writing and Computer-Mediated Communication: A Qualitative Meta-Synthesis of Recent Research 
endeavours.

In computer-mediated writing, there is also the possibility of an expanded audience where the reader is not limited to the instructor but also one's peers (Gebhard et al., 2011) or even family (Arslan \& Sahin-Kizil, 2010). This was observed to have an impact on learner's motivation to write. Learners in Schenker's (2016) and Vurdien's (2013) studies were motivated by curiosity and interest expressed by their peers to make the effort to produce comprehensible output. Similarly, those in Lee's (2010) study were motivated to write because they knew their peers were also reading. However, the motivational factor may be boosted even further with an authentic audience and purpose. Learners in Mak and Coniam's (2008) study worked collaboratively to produce a brochure introducing their school with wikis, and having an authentic audience in mind gave them a real-world perspective. The affordances of CMC mean that learners can have access to authentic speakers of the second or foreign language that they are learning, and this advantage has been investigated in a number of studies focusing on tools such as emails (Mahfouz, 2010) and internet forums. In L2 internet forums, the authentic audience is the L2 community, and learners have to behave in a way that is appropriate to the language culture. Ritchie and Black (2012) found that learners' ability to make themselves understood in such forums raised their confidence, and this achievement motivated them further. Internet forums also give learners the opportunity to participate in the $L 2$ linguistic community, and observe first-hand how negotiations are conducted in that community (Ritchie \& Black, 2012). Therefore, the gains are both linguistic and cultural, as learners gain both communicative competence and knowledge of the $L 2$ community's cultural norms. These can lead learners to be invested in the communicative process (King, 2015).

The audience may not even have to be real, as some studies have shown. In solitary blogging, the activity may not be collaborative and hence no negotiation takes place, but having an imagined audience may spur the writer to produce comprehensible output. The imagined audience is also present in the wiki context, where despite a lack of interaction, learners may be aware of a group of target language speakers (King, 2015). In King's study (2015), learners perceived the approval of the imagined community as important, and this motivated the learners and prepared them for the wider audience of those outside of the classroom (King, 2015).

Interestingly, learners' imagined positions as competent L2 users may result in a lack of negotiation. van der Zwaard and Bannink's (2016) study investigated the phenomenon of non-negotiation in the telling of jokes via videoconferencing and text chat between Dutch L2- English learners and Australian students. They found that for high level L2 learners, their imagined positions as competent L2 users may make admitting to incomprehension of the jokes difficult. A lack of negotiation may not necessarily mean comprehension, as this may mean a saving of face or a preserving of face.

Second and Foreign Language Writing and Computer-Mediated Communication: A Qualitative Meta-Synthesis of Recent Research 
Claim 3: Feedback, Whether Synchronous or Asynchronous, was Beneficial to Learners

One of the affordances of $\mathrm{CMC}$ in the writing process is the opportunity for feedback to be given synchronously, and from more than one person at any given time. Computer-mediated corrective review may also lower affective barriers due to its lack of face-to-face communication (Ho \& Savignon, 2007). However, that is not to say that there are no limitations. Elola and Oskoz (2016) point out that tools are both facilitative and limiting, and feedback is restricted by the medium used. For example, they documented how an instructor could have written a lot more than she did using Microsoft Word. In addition, there might not even be a huge difference in how feedback is administered, as seen in how instructor electronic feedback (track changes comments in Microsoft Word) has been observed to resemble handwritten feedback (Ene \& Upton, 2014).

A number of studies have found positive effects of synchronous CMC on instructor feedback. While asynchronous instructor corrective feedback from the instructor was observed to exert positive influences on writing accuracy, the effect diminished over time (Shintani \& Aubrey, 2016). The asynchronous condition resembles the traditional manner of corrective feedback in that it was given after the text has been constructed, which may lead to a focus on form (Shintani, 2016). In comparison, synchronous corrective feedback had more enduring effects on accuracy. This could be due to learners having not only the opportunity to correct the text while in the process of composing it, hence focusing on both form and meaning, but also access to previous corrective feedback while composing and in the process self-correcting them (Shintani, 2016; Shintani \& Aubrey, 2016). This effect on accuracy can also be seen in how learner uptake of instructor corrective feedback was the highest for grammar-related items, even though instructors tended to focus more on content (Ene \& Upton, 2014). The synchronous condition allowed for internalization, modification, and consolidation. Consolidation, seen in the repeat performance, was unavailable in the asynchronous condition. Hence, synchronous corrective feedback may be considered superior to both asynchronous and traditional corrective feedback because the written form affords reflection, and hence puts less burden on working memory (Shintani, 2016). In addition, due to the nature of asynchronous feedback where the message may be read much later after it has been sent, the tendency to neglect responding to it is higher than in synchronous CMC, which in turn may result in lower interaction (Wang \& Vasquez, 2014).

However, asynchronous corrective feedback has its benefits too. The in-time correction and the convenience of not having to consult a dictionary of asynchronous corrective feedback was rated highly (Shintani \& Aubrey, 2016). Also, learners did not need to be at the same place or access the material at the same time (Ho \& Savignon, 2007). They felt less pressured because of the lack of a face-toface factor. Target-like reformulations, such as recasts and explicit feedback, that retained the original message for noticing and reflection are also possible in asynchronous corrective feedback. In addition to these advantages of target-like reformulations, a post-test examination of writing scores for undergraduate EFL

Second and Foreign Language Writing and Computer-Mediated Communication: A Qualitative Meta-Synthesis of Recent Research 
learners found that the track changes feature in Microsoft Word, where the kind of feedback provided is both explicit and implicit, resulted in even larger linguistic gains in form and content (AbuSeileek \& Abualsha'r, 2014), compared to recasts and explicit feedback.

That said, it has been argued that traditional forms of corrective feedback might be easier, and more effective than computer-mediated means that are limited by design. Paper- and-pencil feedback might result in higher accuracy compared to using Facebook, because of a lack of marking functions which hindered comprehension of the feedback (Dizon, 2016). Ho and Savignon (2007) holds a more positive view of computer-mediated review, but argues that since the aim of peer review is to encourage negotiation of meaning, the lack of an oral communication component makes computer-mediated peer review an inadequate standalone tool. Face-to-face peer review with computer-mediated peer review will be preferred.

\section{Training for peer review.}

Corrective feedback was welcome among learners, if it was from the instructor or someone considered competent enough to provide meaningful feedback. Learners from two studies expressed that the teacher's feedback was authoritative and was the only one that mattered (Arnold et al., 2012; Bibowski \& Vithanage, 2016). While some learners were motivated to give and to receive feedback, the lack of confidence in their own linguistic competence meant that they were more comfortable giving interactive than corrective feedback (Lee, 2010). This discomfort in editing peers' mistakes was reported by a number of studies (Castañeda \& Cho, 2013), due to learners' perceived uncertainty in the accuracy of peers' feedback (Castañeda \& Cho, 2013; Vorobel \& Kim, 2017). Learners in Vorobel and Kim's (2017) study found discussing and providing feedback to peers easier than doing so with the teacher, though they believed that the instructor's feedback would be more honest compared to their peers.

Therefore, a number of studies recommend training learners to give peer reviews (Castañeda \& Cho, 2013; Ho \& Savignon, 2007). Giving learners training in providing constructive peer feedback would help develop their writing skills, and raise their awareness of the type of errors (Vurdien, 2013), hence avoiding an overemphasis on surface errors (Ene \& Upton, 2014). This reflects learners' suggestions to have more structured, explicit guidance on providing peer feedback (Dippold, 2009). Helping learners with metalinguistic knowledge would facilitate peer feedback, through the use of an Error Correction Practice System (Ene \& Upton, 2014).

\section{Automated Writing Evaluation (AWE).}

Another type of computer-mediated feedback that is worthy of attention is that of AWE tools. Li, Link, and Hegelheimer (2015) studied the attitudes of both instructors and learners towards an AWE tool, and investigated how it was used in writing practice and accuracy of the produced text. Since AWE tool picks up grammatical errors, instructors could focus more on non-surface learners' essay organization and

Second and Foreign Language Writing and Computer-Mediated Communication: A Qualitative Meta-Synthesis of Recent Research 
content development. While this reduced the revision load of instructors, concerns about the accuracy of the AWE feedback were raised by both instructors and learners (Lee et al., 2013). Despite the shortcomings, learners perceived that the AWE tool was useful in improving paragraph coherence and essay organization (Hyland \& Hyland, 2006; Ware, 2011).

\section{Claim 4: Learner Attitudes towards CMC in Writing are Generally Positive}

Learners in the majority of the studies showed positive attitude towards CMC in writing in terms of linguistic gains, social and personal goals, gains in grammar, vocabulary and cultural content (Ducate et al., 2011). A heightened awareness of their language use and content creation from Wiki writing (Chao \& Lo, 2011; Kost, 2011), an additional perspective on writing, linguistics assistance from peer editing, and the development of communicative skills (Shang, 2007; Vorobel \& Kim, 2017) were also reported. Learners acknowledged that

collaborative writing improved the overall quality of their writing as they focused on both local and global aspects of their writing (Elola \& Oskoz, 2010; Lee, 2010), and expressed a positive disposition towards the ease of translation using online tools (Miyazoe \& Anderson, 2010). Such collaborative tools also motivated learners to go beyond the scope of their assignment; Wang (2015) found that students in a business English course did more extensive reading and research of their topic, and paid more attention to how they employed the target language.

However, there were negative perception of $\mathrm{CMC}$ in writing. Learners complained about different writing styles, disputes over specific roles in the team, and sharing the responsibility for a shared grade (Kost, 2011). Concerns over being sensitive to others' feelings when providing explicit feedback via a Web 2.0 tool for collaborative work and an unwillingness to incorporate others' feedback were also reported (Vorobel \& Kim, 2017). Technical difficulties were also an issue, as difficulties with network issues and the inconvenience of having to use a computer mediation tool to do work might affect learners' inclination towards CMC tools in writing (Chao \& Lo, 2011).

\section{Claim 5: The Patterns of Interaction in Collaborative Writing are Varied and are Influenced by a Number of Factors}

A number of studies sought to categorize interactional patterns in collaborative writing. The first participatory pattern sees learners engaged in highly collaborative work. This corresponds to Cho's (2017) and Abrams (2016) collaborative group and $\mathrm{Li}$ and Zhu's (2013) contributing/mutually supportive group. Cho (2017) found that the indexes of equality and mutuality were more evenly distributed in this group, and there was also more interaction among all members. Li and Zhu $(2013 ; 2017)$ observed that participants took turns to assume the role of an expert.

The second participatory pattern is what Li and Zhu (2013) terms the authoritative/responsive group, which corresponds to Cho's (2017) facilitator/participants group. In this group, an unequal contribution and yet a

Second and Foreign Language Writing and Computer-Mediated Communication: A Qualitative Meta-Synthesis of Recent Research 
harmonious collaboration may be reflected in Cho's (2017) observation of a high level of collaboration in terms of discussion and writing, but with one member who did more of the facilitation and management of the task.

The third "dominant/withdrawn" group has a marked disparity in participation (Li \& Zhu, 2013; 2017). It had at least one participant who took control over the task, and at least one who adopted a passive stance. The dominant members may not work collaboratively. Contribution was unequal and noncollaborative. However, equal levels of contribution may not necessarily be positive. Abrams (2016) found an interactional pattern where there were generally low level of participation and mutuality among all members of the group. The sequentially additive group, which resembles Storch's (2002) dominant/dominant interaction, sees equal amounts of contributions from each member, but the level of collaboration in terms of editing each other's text was low.

Factors such as task type, personal goals, native-speaker status, and selfperceived competencies may account for the different interactional patterns observed. When a task was meaning-related, a cooperative approach was undertaken (Arnold et al., 2012). Individual members' goals influenced the way they chose to participate and interact in the group (Cho, 2017). Non-native speakers contribute more when they are in triads of similar competence levels, but contribute less when in groups of mixed competence, or in groups with at least one native speaker (Fredriksson, 2014). The influence of the learner's self- evaluation of their own competencies was also seen in Arnold et al.'s (2012) study, where learners appeared to contribute in areas they felt competent to do so, and compensate for areas they perceive as weaknesses. It should be noted, however, that interactional patterns may not remain static for the duration of the task but have been observed to shift according to the needs of the group members and the task as learners engaged in different components of the assignment (Li \& Kim, 2013).

\section{Discussion and Conclusion}

This paper reviewed 60 primary studies published from 2007 to 2017, focusing on $\mathrm{CMC}$ in second and foreign language writing instruction and learning. The key findings are as follows. First, instructor support plays a critical role in ensuring the successful implementation of a CMC tool in the classroom. Second, the affordances of $\mathrm{CMC}$ in enhancing the writer's identity and the presence of an audience can increase learners' motivation to write. Third, both asynchronous and synchronous CMC have shown to be beneficial, and provision of training can enhance the effectiveness of the peer review task. Last, participatory patterns of CMC in writing are influenced by factors such as task type, personal goals, native-speaker status, and self-perceived competencies.

One limitation of this study is that the majority of the empirical research reviewed looked at English as the second or foreign language (75\%, 45 out of 60 articles). This may reflect the reality of second or foreign language instruction globally, or English as the dominant language of the internet. Furthermore, many studies were conducted in the United States (38\%, 23 out of 60 studies). Findings may not be generalizable to other populations. For future research directions, Lin

Second and Foreign Language Writing and Computer-Mediated Communication: A Qualitative Meta-Synthesis of Recent Research 
(2015) suggests to consider unpublished dissertations and meta-syntheses done on this topic.

In terms of pedagogical implications, given all the affordances and benefits of $\mathrm{CMC}$ tools in the writing classroom, the temptation to use them for their own sakes might be there. A careful consideration on how to meaningfully integrate its use is essential to the success of the task at hand.

\section{References}

Abrams, Z. (2016). Exploring collaboratively written L2 texts among first-year learners of German in Google Docs. Computer Assisted Language Learning, 29(8), 1259-1270.

AbuSeileek, A., \& Abualsha'r, A. (2014). Using peer computer-mediated corrective feedback to support EFL learners' writing. Language Learning \& Technology, 18(1), 76-95.

Adams, R., Alwi, N. A. N. M., \& Newton, J. (2015). Task complexity effects on the complexity and accuracy of writing via text chat. Journal of Second Language Writing, 29, 64-81.

Alwi, N. A. N. M., Adams, R., \& Newton, J. (2012). Writing to learn via text chat: Task implementation and focus on form. Journal of Second Language Writing, 21, 23-39.

Amiryousefi, M. (2016). The differential effects of two types of task repetition on the complexity, accuracy, and fluency in computer-mediated L2 written production: a focus on computer anxiety. Computer Assisted Language Learning, 29(5), 1052-1068.

Andujar, A. (2016). Benefits of mobile instant messenging to develop ESL writing. System, 62, 63-76.

Arnold, N., Ducate, L., \& Kost, C. (2012). Collaboration or cooperation? Analyzing group dynamics and revision processes in wikis. CALICO Journal, 29(3), 431448.

Arslan, R. S., \& Sahin-Kizil, A. (2010). How can the use of blog software facilitate the writing process of English language learners? Computer Assisted Language Learning, 23(3), 183-197.

Aydin, Z., \& Yildiz, S. (2014). Using wikis to promote collaborative EFL writing. Language Learning \& Technology, 18(1), 160-180.

Bibowski, D., \& Vithanage, R. (2016). Effects of web-based collaborative writing on individual L2 writing development. Language Learning \& Technology, 20(1), 79-99.

Bygate, M. (2001). Effects of task repetition on the structure and control of oral language. In M. Bygate, P. Skehan, \& M. Swain (Eds.), Researching Pedagogic Tasks: Second Language Learning, Teaching and Testing (pp. 23-48). Harlow, UK: Longman.

Castañeda, D. A., \& Cho, M. (2013). The role of wiki writing in learning Spanish grammar. Computer Assisted Language Learning, 26(4), 334-349.

Second and Foreign Language Writing and Computer-Mediated Communication: A Qualitative Meta-Synthesis of Recent Research 
Chao, Y. J., \& Lo, H. (2011). Students' perceptions of wiki-based collaborative writing for learners of English as a foreign language. Interactive Learning Environments, 19(4), 395-411.

Chen, J. C., \& Brown, K. L. (2012). The effects of authentic audience on English as a second language (ESL) writers: A task-based, computer-mediated approach. Computer Assisted Language Learning, 25(5), 435-454.

Cheng, R. (2010). Computer-mediated scaffolding in L2 students' academic literacy development. CALICO Journal, 28(1), 74-98.

Cho, H. (2017). Synchronous web-based collaborative writing: Factors mediating interaction among second-language writers. Journal of Second Language Writing, 36, 37-51.

Dippold, D. (2009). Peer feedback through blogs: Student and teacher perceptions in an advanced German class. ReCALL, 21(1), 18-36.

Dizon, G. (2016). A comparative study of Facebook vs. paper-and-pencil writing to improve L2 writing skills. Computer Assisted Language Learning, 29(8), 12491258.

Ducate, L. C., Anderson, L. L., \& Moreno, N. (2011). Wading through the world of wikis: An analysis of three wiki projects. Foreign Language Annals, 44(3), 495-524.

Ellis, R. (2005). Planning and task-based performance: Theory and research. In R. Ellis (Ed.), Planning and Task Performance in a Second Language (pp. 3-34). Mahwah, NJ: Lawrence Erlbaum Associates.

Elola, I., \& Oskoz, A. (2010). Collaborative writing: fostering foreign language and writing conventions development. Language Learning \& Technology, 14(3), 51-71.

Elola, I., \& Oskoz, A. (2016). Supporting second-language writing using multimodal feedback. Foreign Language Annals, 49(1), 58-74.

Elola, I., \& Oskoz, A. (2017). Writing with 21st century social tools in the L2 classroom: New literacies, genres, and writing practices. Journal of Second Language Writing, 36, 52- 60.

Ene, E., \& Upton, T. A. (2014). Learner uptake of teacher electronic feedback in ESL composition. System, 46, 80-95.

Fredriksson, C. (2014). The influence of group formation on learner participation, language complexity, and corrective behavior in synchronous written chat as part of academic German studies. ReCALL, 27(2), 217-238.

Gebhard, M., Shin, D., \& Seger, W. (2011). Blogging and emergent L2 literacy development in an urban elementary school: A functional perspective. CALICO Journal, 28(2), 278- 307.

Ho, M., \& Savignon, S. J. (2007). Face-to-face and computer-mediated peer review in EFL writing. CALICO Journal, 24(2), 269-290.

Hsu, H. (2017). The effect of task planning on L2 performance and L2 development in text-based synchronous computer-mediated communication. Applied Linguistics, 38(3), 359-385.

Hwang, W., Chen, H. S. L., Shadiev, R., Huang, R. Y., and Chen, C. (2014). Improving English as a foreign language writing in elementary schools using mobile devices in familiar situational contexts. Computer Assisted Language

Second and Foreign Language Writing and Computer-Mediated Communication: A Qualitative Meta-Synthesis of Recent Research 
Learning, 27(5), 359-378.

Hyland, K., \& Hyland, F. (2006). Feedback on second language students' writing. Language Teaching, 39, 83-101.

Kessler, G. (2009). Student-initiated attention to form in wiki-based collaborative writing. Language Learning \& Technology, 13(1), 79-95.

Kessler, G., \& Bibowski, D. (2010). Developing collaborative autonomous learning abilities in computer mediated language learning: attention to meaning among students in wiki space. Computer Assisted Language Learning, 23(1), 41-58.

Kessler, G., Bibowski, D., \& Boggs, J. (2012). Collaborative writing among second language learners in academic web-based projects. Language Learning \& Technology, 16(1), 91- 109.

King, B. W. (2015). Wikipedia writing as praxis: computer-mediated socialization of second-language writers. Language Learning \& Technology, 19(3), 106-123.

Kost, C. (2011). Investigating writing strategies and revision behavior in collaborative wiki projects. CALICO Journal, 28(3), 606-620.

Lee, C., Kwok, W. W. C., Chi, K. K. W., \& Sau, F. L. L. (2013). Immediate web-based essay critiquing system feedback and teacher follow-up feedback on young second language learners' writings: an experimental study in a Hong Kong secondary school. Computer Assisted Language Learning, 26(1), 39-60.

Lee, L. (2010a). Exploring wiki-mediated collaborative writing: A case study in an elementary Spanish course. CALICO Journal, 27(2), 260-276.

Lee, L. (2010b). Fostering reflective writing and interactive exchange through blogging in an advanced language course. ReCALL, 22(2), 212-227.

$\mathrm{Li}, \mathrm{J}$. (2013). Synchronous text-based computer-mediated communication tasks and the development of $L 2$ academic literacy. International Journal of ComputerAssisted Language Learning and Teaching, 3(1), 16-32.

Li, J., Link, S., \& Hegelheimer, V. (2015). Rethinking the role of automated writing evaluation (AWE) feedback in ESL writing instruction. Journal of Second Language Writing, 27, 1-18.

$\mathrm{Li}, \mathrm{M}$. (2013). Individual novices and collective experts: Collective scaffolding in wikibased small group writing. System, 41, 752-769.

Li. M., \& Kim, D. (2016). One wiki, two groups: Dynamic interactions across ESL collaborative writing tasks. Journal of Second Language Writing, 31, 25-42.

Li, M., \& Zhu, W. (2013). Patterns of computer-mediated interaction in small writing groups using wikis. Computer Assisted Language Learning, 26(1), 61-82.

Li, M., \& Zhu, W. (2017). Explaining dynamic interactions in wiki-based collaborative writing. Language Learning \& Technology, 21(2), 96-120.

Lin, H. (2015). A meta-synthesis of empirical research on the effectiveness of computer- mediated communication (CMC) in SLA. Language Learning \& Technology, 19(2), 85- 117.

Mahfouz, S. M. (2010). A study of Jordanian university students' perceptions of using email exchanges with native English keypals for improving their writing competency. CALICO Journal, 27(2), 393-408.

Mak, B., \& Coniam, D. (2008). Using wikis to enhance and develop writing skills among secondary school students in Hong Kong. System, 36, 437-455.

Second and Foreign Language Writing and Computer-Mediated Communication: A Qualitative Meta-Synthesis of Recent Research 
Miyazoe, T., \& Anderson, T. (2010). Learning outcomes and students' perceptions of online writing: Simultaneous implementation of a forum, blog, and wiki in an EFL blended learning setting. System, 38, 185-199.

$\mathrm{Ng}, \mathrm{C}$. H., \& Cheung, Y. L. (2019). Current trends and future directions in pre-service teacher training programmes for English Language in ASEAN Plus Three: A synthesis of recent research. In S. Zein \& R. Troupe (Eds.), English language teacher preparation in Asia: Policy, Research and Practice (pp. 19-44). Abingdon, UK: Routledge.

Ng, C. H., \& Cheung, Y. L. (2017). Innovations in writing instruction in China: Metasynthesis of qualitative research for the decade 2005-2016. In H. Reinders, D. Nunan, \& B. Zou (Eds.), Innovation in Language Learning and Teaching: The Case of China (pp. 63-87). Basingstoke, UK: Palgrave Macmillan.

Ortega, L. (2009). Second Language Acquisition. London: Hodder Education.

Oswald, F. L., \& Plonsky, L. (2010). Meta-analysis in second language research: Choices and challenges. Annual Review of Applied Linguistics, 30, 85-110.

Ritchie, M., \& Black, C. (2012). Public internet forums: Can they enhance argumentative writing skills of L2 learners? Foreign Language Annals, 45(3), 349-361.

Rouhshad, A., Wigglesworth, G., \& Storch, N. (2016). The nature of negotiations in face-to-face versus computer-mediated communication in pair interactions. Language Teaching Research, 20(4), 514-534.

Sauro, S., \& Smith, B. (2010). Investigating L2 performance in text chat. Applied Linguistics, 31(4), 554-577.

Schenker, T. (2016). Syntactic complexity in a cross-cultural E-mail exchange. System, $63,40-50$.

Shang, H. (2007). An exploratory study of e-mail application on FL writing performance. Computer Assisted Language Learning, 20(1), 79-96.

Shintani, N. (2016). The effects of computer-mediated synchronous and asynchronous direct corrective feedback on writing: a case study. Computer Assisted Language Learning, 29(3), 517-538.

Shintani, N., \& Aubrey, S. (2016). The effectiveness of synchronous and asynchronous written corrective feedback on grammatical accuracy in a computer-mediated environment. The Modern Language Journal, 100(1), 296-319.

Storch, N. (2011). Collaborative writing in L2 contexts: Processes, outcomes, and future directions. Annual Review of Applied Linguistics, 31, 275-288.

Strobl, C. (2014). Affordances of Web 2.0 technologies for collaborative advanced writing in a foreign language. CALICO Journal, 31(1), 1-18.

Sun, Y., \& Chang, Y. (2012). Blogging to learn: becoming EFL academic writers through collaborative dialogues. Language Learning \& Technology, 16(1), 43-61.

van der Zwaard, R., \& Bannink, A. (2016). Nonoccurrence of negotiation of meaning in task-based synchronous computer-mediated communication. The Modern Language Journal, 100(3), 625-640.

Second and Foreign Language Writing and Computer-Mediated Communication: A Qualitative Meta-Synthesis of Recent Research 
Vorobel, O., \& Kim, D. (2017). Adolescent ELLs' collaborative writing practices in face-to-face and online contexts: From perceptions to action. System, 65, 78-89.

Vurdien, R. (2013). Enhancing writing skills through blogging in an advanced English as a Foreign Language class in Spain. Computer Assisted Language Learning, 26(2), 126- 143.

Wang, S., \& Vasquez, C. (2014). The effect of target language use in social media on intermediate-level Chinese language learners' writing performance. CALICO Journal, 31(1), 78-102.

Wang, Y. (2015). Promoting collaborative writing through wikis: A new approach for advancing innovative and active learning in an ESP context. Computer Assisted Language Learning, 28(6), 499-512.

Ware, P. (2011). Computer-generated feedback on student writing. TESOL Quarterly, 45(4), 769-774.

Yeh, H. (2014). Exploring how collaborative dialogues facilitate synchronous collaborative writing. Language Learning \& Technology, 18(1), 23-37.

Yeh, S., Lo, J., \& Chu, H. (2014). Application of online annotations to develop a webbased Error Correction Practice System for English writing instruction. System, 47, 39-52.

Yilmaz, Y. (2011). Task effects on focus on form in synchronous computer-mediated communication. The Modern Language Journal, 95(1), 115-132.

Second and Foreign Language Writing and Computer-Mediated Communication: A Qualitative Meta-Synthesis of Recent Research 